\title{
Children's Books about Special Needs Used as a Mediating Tool, The Perceptions of Inclusion Classroom Teachers in Mainstream Schools
}

\author{
Baratz Lea ${ }^{1}$ \\ ${ }^{1}$ Department of Literature, Achva-College of Education, Israel \\ Correspondence: Baratz Lea, Department of Literature, Achva-College of Education, Israel. Tel: 972-8-939-6720. \\ E-mail: 1baratz@netvision.nwt.il
}

Received: December 9, 2014

Accepted: January 9, 2015 Online Published: January 21, 2015

doi:10.5539/hes.v5n1p51

URL: http://dx.doi.org/10.5539/hes.v5n1p51

\begin{abstract}
The current study addresses the disparity between the awareness of teachers in special education frameworks regarding the important role of books as a mediating tool and their reticence to use this tool. Twenty three interviews were conducted in two stages: before and after using the book Shelley the Hyperactive Turtle in the classroom. Interviews attempted to examine teachers' perceptions regarding the use of the book with a student population that has the disorder featured in the book. Even while teachers expressed awareness of the importance of books as a mediating tool, they explained their reasons for refraining from integrating books that are not part of the official curriculum in the course of their work. The findings indicate the need for a novel approach regarding the inclusion in the curriculum of books that feature learning disorders, while simultaneously addressing teachers' emotional needs and expanding their knowledge of the bibliotheraptic process. In this manner, books, which have a recognized and distinct mediating role, can become a significant and useful tool for teachers.
\end{abstract}

Keywords: Attention Deficit Disorder, inclusion classroom, children's books, mediating

\section{Introduction}

Over the last decade, education systems have developed an increased awareness of children with special needs. The educational philosophy has changed, and the new tendency is to include in mainstream schools children who in the past would have been sent to special education frameworks (Balas \& Laor, 2002). This perception was grounded in legal terms in the Special Education Law of 1988. The idea underlying this philosophical shift is to provide all children with access to equitable education, with the goal of approaching social normalization, by including children with special needs in the company and in the activities of children attending mainstream schools (Avisar \& Laser, 2000). Prior to this shift, many children with special needs and among them children with attention deficit/hyperactivity disorder (ADHD) were directed special education frameworks that were completely separated from mainstream institutions (Avisar \& Laser, 2000).

In the context of the Special Education Law, which calls for the inclusion of students in frameworks that are less separate from the mainstream, the needs of children are addressed within the inclusion classroom, by altering teaching methods and developing patterns for cooperation between mainstream teachers, special education teachers, and professionals providing various types of therapy. The large range of students' needs and the varying severity of their difficulties mandate that the educational and the therapeutic frameworks continually operate on a single continuum, with characteristics that vary by school and by the national education system with which they are affiliated (Margalit, 1997).

There is a substantial disparity between the way teachers approach students with special needs and their approach to mainstream students. Students with special need are considered slow, noisy, and a source of disruption; consequently, in many cases teachers are deterred by these behaviors and develop a negative approach. In contrast, mainstream students are perceived in a much more positive light (Talmor, Asia, \& Kayam, 2010). In addition, teachers face a complex situation in which, on the one hand, they are expected to demonstrate sensitivity, consideration, empathy and to be able to cope with students with special needs, while on the other hand, they are expected to convey to students with special needs that they believe in their ability to succeed both academically and socially (Talmor, Asia, \& Kayam, 2010). Most often, teachers face these conflicting demands without ever having received any form of guidance or support. The current study contributes to the professional 
literature by conveying teachers' perspectives regarding their use of a children's book in the classroom, which could serve as a source for the personal empowerment of both the teachers and the student readers, in a case focusing on ADHD.

\subsection{The Coping of Teachers}

In the classroom, the special needs of students are expressed in ways that are disruptive to teachers, who consequently, either unconsciously or consciously, develop oppositional approaches to the students. Thus, the children are viewed as heading for failure and a source of frustration, in contrast to the rest of the children in the classroom. In social terms, these children are rejected, with the exception of their belonging to the group of class clowns. They are not popular and they are most often excluded from games and social activities. By comparison, the children who do not have gross motor or coordination difficulties and who excel in athletics are those who are popular and esteemed by their peers (Dar'in, 2001). Children with special needs are apt to exhibit low self-esteem, changeable moods, anxiety, and depression, as well as other difficulties which are less common.

\subsection{Literature as a Socializing Agent}

The teaching of literature is effective as long as students feel that they have learned something new about themselves which they had not been aware of previously. The more students are exposed to a broad variety of age-appropriate literary works that correspond to their level of comprehension and to their internal emotional needs, the more their sociocultural world will expand and they will be better able to internalize the experience. An educator, who does not read for his or her own enjoyment and learning will not be able to teach students the love of reading (Shach \& Green-Shukrun, 2009).

For children, reading literature has a significant role in expanding their knowledge, developing their verbal abilities, and addressing mental needs; yet, beyond all of these the literary work constitutes a therapeutic tool (Shach \& Green-Shukrun, 2009). Every valuable literary work expresses a worldview, which calls upon the readers to examine their own views; it can even lead readers to abandon their current worldviews and to adopt new perceptions that they did not have beforehand (Baratz \& Kass, 2007). Literary texts are important for the development and construction of a culture and facilitate an understanding of human life. Literary texts written for children play an even more important role, due to their significant impact on the development of the individual child's personality, as they reflect ideologies, values, norms, and acceptable behavior patterns (Rosenthal, 2006).

Over the years, teachers and librarians have used books to help people both with and without special needs to understand certain situations. Nowadays, acknowledging the therapeutic effects of bibliotherapy with various populations, books are used to help educators understand their students and their needs (Karen \& Stephanie, 2011).

Marlowe and Maycock (2000) noted that with the help of books, teachers develop empathy and understanding towards the special needs of their students and are able to address the differences among their students. Exposing educators to the literature that focuses on children and youths with special needs is important, as it enables educators to identify the strengths and weaknesses of each student. It is of vital importance that educators be trained and receive proper guidance, so that they will be able to use bibliotherapy as a proper and effective tool that has the dual advantage of helping students with special needs understand that they are not alone and simultaneously helping other students in the classroom appreciate their classmates and the difficulties they experience. Hence, literary works should be selected with great care, paying attention to the details that can increase awareness and encourage processes significant for personal development (Marlowe \& Maycock, 2000).

According to the humanist approach to education, teachers are responsible for the development of their students. School is more than a place where knowledge is transferred; rather, it is a place where students have the opportunity to experience the mental and emotional processes that are part of human development and that will enable them to become integral members of society (Baratz \& Kass, 2007). Educators share the responsibility for students' developing into and becoming mentally secure adults, with social skills and a well-formulated and value-based worldview. Teachers who are aware of the students' needs and inner world are likely to have a positive effect on students' self-image and self-confidence, as they provide a protected learning environment governed by value-based rules. Thus, teachers must be prepared and allowed to acquire the skills to create a conative, emotional, and morally-grounded learning environment. According to Morawski (1997), teachers themselves should be equipped with a great deal of knowledge in bibliotherapy. When used properly, the tool can have a positive effect on teachers in both the personal and professional realm. The process the teachers undergo is comprised of three stages: (1) identification - the ability to examine behaviors and place oneself in another's shoes; (2) purification-addressing each case from both a personal and a professional perspective; (3) 
insight — after being released from personal opinions, the issue is addressed intellectually and from an emotional distance. The teacher too is a person with needs, beliefs, and emotions; nevertheless.

To use this tool effectively, and to expand their knowledge, teachers should read a variety of texts, for example, children's literature, fairy tales, history, and other genres (Catalano, 2008). The world of the child, and even that of the adult, is confusing if it lacks rules and an organizational framework; therefore, the teacher, as an agent of change, can serve as a role model for the young students. Teachers who are aware of their own behaviors and of the potential impact of their behaviors know how to use these for the child's benefit. The teacher who talks with students about emotional content is likely to have a dominant role in the child's world. Bibliotherapy can serve as a means and an instrument in the hands of teachers who feel a sense of responsibility for the child's emotional inner world (Baratz \& Kass, 2007).

The selection of the book that will be used for this purpose is a very significant stage, since the choice of an inappropriate book could cause emotional and mental damage. The book should be chosen based on age appropriateness, the level of the child's reading skills, the realistic characters it presents, and the quality of the story it tells (Prater, Johnstun, Dyches, \& Johnstun, 2006). The use of a book facilitates the teaching of any topic and allows for the discussion of issues, which without the mediation of the book would be inaccessible (Catalano, 2008). The manner in which the educator guides and mediates the literary text for the students is crucial, as it can determine whether the process is utilized to the fullest effect (Tal, 2010).

\subsection{Children's Books that Reflect a Learning Disability}

Children's literary works that tell a story about a child with a learning disability reveal four types of possible encounters between the mainstream child and the child with special needs. Sacerdoti (2013) refers to a "model of four encounters": the absence of an encounter; the encounter between "self and other", which refers to a random, momentary, yet emotionally loaded encounter between a mainstream child and a child with special needs; an "I-thou" encounter, which is imposed on the participants, who have no choice in the matter (e.g., living alongside a relative with special needs); and an informed encounter with the voice of the child with special needs. However, the child's unique perspective and the manner in which a child with special needs copes with this existential challenge are at the heart of literary texts that that are used in bibliotherapy with children.

These literary works are intended for three kinds of readers: the first group is children with special needs, for whom these texts have the function of a therapeutic catharsis. Through the literary work, these children can understand that they are not alone, that there are other children who also are coping with similar challenges, whether related to a deficiency, a disorder, or a disability; thus, they are able to learn of different ways of coping. The second target audience consists of mainstream children, who are exposed to the world of a child with special needs through the literary work. In this case, the underlying assumption is that knowledge can draw people closer. By addressing these two types of audiences simultaneously, these literary works construct an extra-literary, discursive encounter, which is based on an "I-thou" encounter. The third type of audience addressed by these works is the adult, the parent, or the professional, who provides a support system for this encounter. In these books, the difficulty is given a precise name and an explanation. The linear plot development that presents the problem, the coping, and the realistic and tenable solution provides insight into the world of many other children, who are constantly coping with the demands of the competitive society in which we live. The literature becomes a "mirror" of sorts, through which the readers see how they are perceived by others, and at the same time, it allows them to perceive their ontological essence, as it is reflected in the storybook character (Lindsay, 2006).

\subsection{The Adult as Mediator}

Mediation is necessary due to the distance in time and space between the authors of the text and their potential audience, which makes it impossible for the authors to engage in direct discourse with the audience; hence, they must write for a "virtual reader". As a result, the author, either consciously or subconsciously, lets this virtual reader dictate the linguistic register of the text, i.e., its syntactic complexity and the inclusion of verbal and cultural connotative references in the work, as well as the sophistication of the plot (Cochran-Smith, 1986). Shavit (1996) noted that the issue of mediation is important, because there are several subjects that are taboo for children.

Feuerstein $(1979,1980)$ provides criteria for defining mediation. According to his approach, interaction between parent and child is considered a mediated learning experience if that is the express intent of the adult and the adult conveys this intent to the child. A second criterion requires that the adult's actions correspond to the situation of the particular child, and that throughout the interaction; the adult provides emotional, ethical, and cultural interpretation of stimuli. An interaction is considered an act of mediation if it conveys a set of rules, regulations, and processes beyond those demanded by the immediate context that gave rise to the interaction. 
According to Feuerstein, in the mediation process, while addressing the task at hand, the mediator must draw children's attention to their own ability to monitor the pace and intensity of their conscious activity. In addition, the mediator should express satisfaction with the child's behavior, identify the components that led to the positive behavior or outcome, and provide the child with feedback regarding the successful performance.

According to Klein (1996), the mediation is important, because the reciprocal interaction between the adult and the child leads to an enriching learning experience for the child. The main goal of the mediation approach is to affect children's range of needs, specifically, to stimulate in children needs that will lead them to develop the motivation and skills for learning in the future. These needs include, for example, the need to be focused on something; the need to find significance and meaning; the need to inquire about past, present, and future experiences and to be able to draw connections between them; the need to succeed and be esteemed by others; the need to assess one's own actions, and to plan before executing an action.

The mediation approach — even when experiential (Shach, \& Green-Shukrun, 2009) —is flexible, as it allows for a variety of interpretations and adjustments, according to the needs of children from diverse cultures and environments (Klein, 1996). The current study examined the views of teachers working in inclusion classes of their experience mediating a children's book that describes the challenges of a child with ADHD.

\section{Methodology}

\subsection{Data Collection}

For the purpose of the current study, guided and focused interviews were conducted. The interviews dealt with the educators' feelings and emotions regarding their experience of teaching and mediating the storybook Shelley the Hyperactive Turtle. The selected book tells the tale of Shelley the turtle, a character that represents many school-aged children who have ADHD. In the story, Shelley seeks ways to overcome the difficulties related to ADHD and copes with the associated stigma. Each day he repeats his decision and promises to start anew and behave properly, as is required. However, when he does not succeed, he turns inward and closes himself to the outside world, as indeed many children with ADHD tend to do.

The rationale for selecting this story is based on the principle of "the good story" (De Malach \& Poise, 2006). This term refers to three criteria: the psychological criterion, which measures the personal experiential outcome of the reading for the individual as formed through the reading of the story; the moral criterion, which assesses the story in terms of the didactic products it contains; and the aesthetic criterion, which relates to the objective assessment of the story as an art form. Through the reading process, the reader becomes better acquainted with the character of Shelley the turtle, an affable character, with whom many children with ADHD can identify.

In the course of the interview, the teachers were asked to tell how they integrated the story into their work. Interviews were open-ended, and began with an opening question, after which the conversation flowed naturally and freely. The interviews were conducted in a relaxed atmosphere and lasted between 40 minutes and one hour. Eight of the interviews were conducted at the home of the teachers and seventeen were conducted at the school where the teachers work. With the participants' consent, the interviews were recorded and transcribed, and participants were assured that whatever was said during the interviews would be used solely for the purpose of research, while maintaining their anonymity.

The participants were 23 female teachers employed in mainstream education and teaching in state-funded secular Jewish elementary schools (most of the teachers in Israel are female). Participants' teaching experience ranged from one year to 30 years and their age range was from 25 to 55 years old. Eight of the participants had not received training in special education and were teaching in mainstream inclusion classes, in which approximately $10 \%$ of the students had special needs. The remaining 15 teachers had been trained to teach in a special education framework and were teaching special education classes within mainstream schools. Of these 15 teachers, five were teaching transition classes, i.e., classes with small groups of children with special needs, who were preparing to be assigned to inclusion classes. Recruitment of participants was based on the researcher's professional acquaintance with the teachers.

\subsection{Method of Analysis}

Findings of the current study were analyzed using the grounded theory method, described by Glaser and Strauss (1967). The first stage, the coding and development stage consisted of a close, paragraph by paragraph, analysis of the interview transcripts. The topics identified were named in a manner that reflected their contents, for example, the teacher's worldview; the book as a mediator; the book's contribution. The second stage consisted of axial coding, which is intended to refine the categories identified and find connections between them. This stage revealed various aspects of the teachers' work process; of these, two major categories were selected for in-depth 
analysis and description (see Findings section). The third stage involved developing a theory to explain the reasons behind teachers' reticence to include children's literature in their work plans, despite their awareness of children's books' mediating role.

\section{Findings}

Findings relate to the two categories concerning the use of the book as a mediating tool: (a) the role of the story in terms of the teachers' work process, and (b) the story's overall contribution, as viewed by the teachers.

(a) The role of the story in terms of the teachers' work process

When asked regarding the book's contribution, teachers related to the following topics.

\subsection{The Book as a Source of Information}

The teachers (fourteen) explained that the book did not add any new information beyond that which they already possessed. A phrase that was used repeatedly in numerous variations was "the book itself did not contribute new information or new knowledge about ADHD; the book added nothing, as far as I'm concerned." Another typical response was "in terms of knowledge, I don't think I learned anything new from the book... These were things that I knew already... Mostly, I learned about my students and how they cope with the topic of the book."

Although the book did not add new information or knowledge about the essence of ADHD, it did help the teachers understand the related challenges their students face. Thus, the book provided the teachers with a type of information beyond the book's intended scope, which is to create an emotional experience for the readers.

\subsection{A Change in the Work Process-A Variation in Teaching Style}

The book was used to fulfill predefined goals, for example, serving as an experiential stimulus; providing a framework for the process of verbal, cultural, moral socialization; and creating an aesthetic experience. Teachers (sixteen) commented that the book provided a resource for adding variety to the learning experience. The following three excerpts from interviews serve as examples.

"Teaching with the book, and using it to mediate the learning, enriched my teaching experience, by adding a different way of teaching... Today, there is a wide range of books on numerous topics, which helps professionals address various topics in an experiential way and influence the students' emotions, thoughts, personality, and so forth... It gave me the opportunity to deal again - in a nonconventional way-with a topic that is manifested in class on a daily basis, using a text I had never used beforehand.” (Romi)

"I have already used a book for mediating as part of my work as a teacher and educator. I believe in-and practice - the use of multiple techniques and teaching instruments. I find it very important to enrich the students' learning experience in various ways, using aides that can be brought into the classroom. ... I learned of a different way to explain to the children what ADHD is. " (Noa)

"In emotional terms, I gained a better understanding of the difficulties that children with ADHD experience... In my opinion, the book serves to facilitate discussion, ask questions, and provide new information that is related, for the most part, to the child's experiences and emotional world, and which can help the child see things from a different perspective. Sometimes the book can provide students with a new way to find solutions to various situations encountered in daily life. And, as I mentioned before, I think children are more comfortable identifying with and talking about the fictional character than about themselves." (Yona)

The teachers described the experiential work process in generalized terms. They used the word "way" as a metonym (a detail used to represent an entire world). The word they chose to use, way, emphasized that it could refer to means, instruments, or activities, all—or one-of which could be used to alter the conventional work processes in the classroom.

\subsection{The Experience of Identifying with the Character}

According to the teachers (eleven), the book offers a different way to convey messages, a way that is based in experience and in which the contents of the lesson hold a different type of attraction for the students. The following two examples are excerpts from the interviews with the teachers.

"The book facilitates a nonconventional type of learning, a different kind of learning, which occurs through the experience of identifying with the character. The characters are all animals, which makes the children who are listening to the story identify with the characters instantly." (Noa)

"Learning with a book is effective; the book creates interaction, motivation, and identification with the contents described in the book. Using the book can help teach values, behaviors, and situations of the type 
encountered on a daily basis, much more so than listening to, or speaking about, or understanding information presented in a text... Books written for children are very important both on the personal and on the social level. Through a book, a child can encounter difficult and emotional events, some of which are already familiar to the child and others which are less so. Reading books that are relevant to the topics being studied is indeed a very enjoyable experience!" (Sani)

The teachers (most of them) reported that the students were not the only ones who had a unique and different learning experience, as they too had a personal emotional experience:

"On the personal level, I felt much moved. I felt bad for the sweet turtle who wants so badly to be like everyone else, he tries to succeed but gets frustrated... The book is an instrument that provides an enjoyable experience and helps create a therapeutic effect. The book mediates: it helps me convey a message, helps students, and occasionally enables them to understand their situation... It's cute and amusing to personify animals by presenting them as hyperactive and of course they too can receive therapy. Relatively speaking, I have a breadth of knowledge and experience, as each year at least six students with ADHD are assigned to my class and I am familiar with its characteristics and therapeutic approaches --not only the medicinal one." (Ela)

"I was very moved by the book. The choice of a turtle as the hyperactive character enables the child with ADHD to identify with the character. This feeling of identification is very similar to the type of therapy that uses parables with animal characters... The book can serve as an instrument that mediates to children with ADHD: it enables them to identify with the character, to air out emotions, and provides others with the opportunity to understand and accept the other. A book can also help resolve social problems among the children". (Yonit)

While many of the interviewees noted having had an emotional experience through reading, some of them (eight) mentioned in this context that as they were reading the book to the children, they noticed the extent to which the book created an emotional experience for the children listening to the story.

\subsection{Personal Enrichment}

The teachers thought that their students identified with the characters and that this sense of identification helped the students with their own difficulties. The story enabled them to adopt a more optimistic attitude regarding these difficulties. A few examples follow.

"This book is very important, because in fact it helps children understand that they are not alone and that this is something that can be coped with. Many times something like this can be very intimidating-children do not understand what is causing this [difficulty] and they receive reactions from their environment." (Ela)

A different teacher noted the following:

"The book creates an experience that can serve to mediate; however, several mediating steps should be devised as part of the teachers' preparation for teaching the book. These steps are dispersed throughout the different parts of the story and, of course, at the end, where the real process of applying what was learned through the story begins." (Yonit)

"Integrating the use of books in the daily activities of the class affords the opportunity to encounter students' thoughts and feelings. We conduct discussions on a variety of situations, which are derived from the reading, and which are related to their personal, emotional, and social world. I noticed that students feel more comfortable identifying with and speaking about the character than about themselves... For me, the book presents a window of opportunity to develop a discussion that piques students' interest and leads them to identify with the protagonist." (Yael)

Yet another teacher noted the following.

"The book can mediate between the world of the adults and the world of children. Many times younger children find it easier to identify with the protagonist of the story and to speak using the third person than to speak [directly] about themselves and their experiences." (Sani)

Thus, it appears that the teachers wish for their students to experience a process that has personal, developmental, and social implications. Moreover, the teachers' ultimate aspiration is that following a reading experience that transcends the boundaries of "reading for learning" students will experience the process of creating meaning. However, it appears, based on their reports that this process is in fact missing. 


\subsection{Teachers' Feelings about the Book}

Findings indicate that the teachers are aware of the book's importance and of its contribution on several levels: on the didactic level, they see that the children are able to understand and internalize the message of the story; on the level of language arts, they see that students can enrich their vocabulary without reducing their enjoyment during the reading of the story; on the moral level, they are able to teach and promote certain values; and on the emotional level, they noted that each individual student is exposed to different aspects and empowered in different ways. Nonetheless, a sense of uncertainty and reticence was noticeable in their responses.

\section{A. A tone that relates a positive message.}

It is important that first of all the book should be close to the children's world and not create any kind of frustration, in other words, its level should not be high enough but not too low. On the one hand, it should enrich their vocabulary, but on the other hand, the child can identify with and understand the story.

"... it is possible to nurture and teach values, through all kinds of stories that we see and in which the child's difficulty — as well as solutions — can be recognized within the story, and then we can ... For example, if something happened in the classroom and we want to find a solution, then we can use this story. It's easier, because you speak as if about someone else and then the children are able to express their thoughts more freely. And, there's another worthwhile thing... that children like very much-which is parables. They love the animals, and as the story is about animals and not about people, and then it's easier for us, because it's not [about] us, but we can still learn something about ourselves." (Yonit)

Another teacher had this positive take on the use of books.

"We actually convey a message about treating and accepting the other. There is also the special program "The heart key" which is taught nowadays at school, and so every month we focus on a particular value. So while it's true that my personal worldview is that teaching values is mostly done through activities in which we apply the value,- - but also through stories....Also through a story... While it's true that the strongest message comes through actually applying the value, in other words, if I want to teach children the... um... um... how to treat others, then - how can I lead the child to want to help others?... Now the month of Shvat is approaching and so, most likely, we will be teaching a value related to giving and to nature, so in that too... We can teach the value in a way that corresponds with all the different directions do you see?-Through stories, by inculcating...-Do you see through all of the senses? "(Yael)

\section{B. A tone of hesitation about the book's significance.}

Even as they understood the important contribution of the book, the teachers' (ten) were essentially circumspect regarding the use of this tool. The four examples that follow express this hesitance.

"However, as a tool that actually encourages discussion, it's a little, um... I don't know... I find this difficult, because I feel I don't have enough tools to use this... I try to avoid it. If I do use it, I do it through the "The key of the heart" or teaching life skills or resilience. I could_let's say-bring them a book about being different due to a disability, because in my class there are no students with disabilities. I just don't want to make them feel different."(Sani)

"Many times I choose to address things directly, rather than through the use of a book. The book is an additional means to strengthen [the message] and also a pleasant way to convey the message through an emotional experience. When I choose a book... I tend to choose a book that conveys or highlights a particular value and leaves room for thought. ... The considerations that lead me to use a book... um... For example, when I know that a child with a particular difference is about to join the school, I choose to discuss this with the students and occasionally I'll use a book... Or when I see the way students respond to someone different... Often students ask me to address this directly..."(Ela)

"When choosing the stories I need to teach in class, I usually follow the curriculum. I'll choose stories that are related to the students or stories that provide an opportunity to teach according to the curricular goals for that particular month. In addition, I choose a from a variety of books that convey a message, a situation, or an event that is relevant to things that occur in daily life in the class, in terms of all aspects: didactic, social, and so on..." (Ronit)

"A book has many advantages especially for conveying a message that could offend certain students; the message is not direct; thus, children find it easy to identify with characters from the stories, and they have a clear understanding of the message and, indirectly, they understand its implication for them, their acts, their behaviors, and their way of life in general. I'll choose a book that is on an appropriate level for the 
children to comprehend, and with a message that suits my goals. The books I usually choose to read from are plot-based stories that will attract and interest the listeners [the children], books that have a clear and unambiguous message and which suit my needs. I usually choose books or stories that correspond to didactic or value-based goals, books that will cause the listeners [the students] to identify with the appropriate characters. "(Dana)

The teachers' hesitance is revealed through their stammered delivery and the convoluted language, which ultimately does not provide a clear answer explaining why they choose the books they do. The teachers' reticence is laden with excuses, presumably in an attempt to dodge responsibility. Teachers demonstrated this attitude even though they thought that the book is "a wonderful classroom tool" that helps them deals with social and behavioral problems that occur in class. They believe it is very important to expose the children in general - and children with special needs in particular - to books with a bibliotherapeutic effect, or as they put it, "it's a wonderful therapeutic method". They recognize that the book develops and enriches the child's imaginary world and vocabulary. However, they are afraid to delve into areas that touch on the children's emotional world, and they go to great lengths to ensure the children's physical and mental health.

C. Reasons to avoid using books.

The following reasons were mentioned.

1) A preference for unmediated and direct discussion

According to the teachers (seven), one of the reasons for avoiding the use of books was their preference to conduct unmediated, direct, and open discussions with the students regarding "problems" that surface during the learning process. "I use the book as a mediating tool infrequently, due to the fact that I favor presenting the situation itself... The society in which we live promotes values of openness in all realms; therefore, as teachers, we generally use the direct teaching method, rather than the indirect method, for fear that students might not internalize the message, the goal of the learning. That's why we prefer to "call it as it is"-in other words direct teaching - that way we are certain that the message has been conveyed and the goal-achieved."(Yael)

Findings suggest that teachers prefer to raise the topics for discussion on their own, while they adapt the level, the message, and the goals to the cognitive and emotional abilities of the students.

2) Teachers lack the necessary tools

Another reason that emerged from the teachers' interviews was that they lack the tools for choosing an appropriate book (most of them), for using bibliotherapy appropriately, and for engaging in client-therapist-type interactions.

"I try not to choose books that might raise traumatic issues, since I do not have the tools to address these if they do arise. I think of books that can enrich students' learning experience in different subjects, with as little connection as possible to personal/emotional context."(Yonit)

This teacher combines two explanations that are not actually related to each other, but rather they are related to her professional identity. If the problem were lack of tools, a teacher might be expected to acquire the necessary tools, by expanding her knowledge base on the topic of bibliotherapy, and in this manner, this teacher would manage to cope with a text that has emotional implications. "I'm not sure I have enough tools or enough knowledge to cope with the emotional experience, so obviously I wouldn't [take it upon myself to] create this experience in others."

Beyond the difficulty of "touching upon" sensitive topics through the use of stories, the teachers believe that bibliotherapy can be more beneficial for mature students, with higher cognitive and verbal levels. In their opinion, discretion should be used in choosing a book, based on the criteria of age, cognitive, verbal, and emotional levels.

However, there were teachers who expressed reticence from a more personal perspective. In other words, they feared that their level of personal knowledge would not enable them to deal with such a sensitive topic. This is how another teacher expressed her hesitance:

"A book that mediates emotional issues is more intimidating [for teachers], because I fear I will not know how to react or how to cope with whatever might surface as a result of the reading experience. Studies related to teaching and education does not deal with ways of handling students' reactions or emotions to personally sensitive issues. In addition, the stress of the job's daily demands and the need to educate students about values creates a sense of confusion for me, as I fill the role of student counselor: so am I an 
educator or a psychological counselor? We demand that students recognize boundaries in everything and I believe that here too, there is room to take define the boundaries of the role of educator as compared to the role of student counselor. I can manage a personal dialogue with a student, where I listen and try to help and obviously rely on others to provide the necessary help; however, this is beyond the scope in the context of the classroom or a small group, where I would have to cope with situations for which I have no training..." (Ella)

These words expound on the same idea noted by other teachers, yet they add the aspect of the teacher's professional status and the precise role she plays in the school.

3) Time constraints

Teachers (sixteen) referred also to time constraints to explain the difficulty of using books that are not included in the official curriculum. The teachers repeatedly emphasized their commitment to the official curriculum and the time allotted to teach whatever is included in that framework, which poses a constraint and precludes the use of other texts. Even though these books might have added value, the practical considerations must prevail. Other comments were related to teachers' burden: "in addition, we are so overburdened with so many things that the importance of this is reduced to a minimum"... Or, as another teacher put it, "we are so overburdened with work; as it is, my responsibilities are endless." Other teachers claimed the following: "I'd never seen this book before..." or "I don't usually work with the book unless it's part of the curriculum and if I choose a book it too will be part of the curriculum framework."

The issue of time constraints can be associated with the absence of tools or knowledge. It is similar to the absence of know-how: “because I didn't know about it, I was never introduced to this... I used books whenever I have the opportunity. As a teacher of a transition class, I'm obligated to follow the curriculum of the mainstream class."

The phrases "I was never introduced to this" and "obligated to follow it" are elegant ways of avoiding responsibility for this "non-choice". Seeking an external locus of control is not typical of a mature approach and is not befitting teachers who are responsible for teaching others how to learn.

4) Insufficient resources

"There is no budget for purchasing books that are not part of the official curriculum. These books are not purchased by the school, and I certainly am not about to pay for them out of my own pocket." Although this reaction reflects a realistic approach, it is not an educationally worthy of consideration.

5) Fear that students will fail to internalize the message

Apparently, teachers (fourteen) do not think that exposing students to the book would contribute to the students' understanding of the topic. Moreover, according to the teachers, the book might even confuse the students, who often have difficulty in reading comprehension. Therefore, most often they prefer to convey these and other messages on their own. For example, to convey the message of acceptance of the other, they would conduct a class discussion and would refer to this directly, rather than through the use of a story.

"We're afraid that students might not internalize the message or the goal of the learning experience. Consequently, we prefer to "call it as it is", in other words, to teach it directly and that way we can be sure that the message has been received and the goal achieved." (Danna)

Another teacher put it thus:

"Often, it might be easier to identify with a character in a book than with people in real life; however, in my opinion, this calls for a high level of thinking and comprehension, in order [for students] to understand the book on their own. This is a very difficult task for my students. It calls for a more abstract understanding and the ability to see how this insight is applicable to real life." (Hen)

\section{Discussion}

The research question sought to examine the role of a book as a tool for mediating, and its effect on the educational approach and the work process of teachers as they relate to students with ADHD. On the one hand, teachers expressed understanding and recognition of the importance and the contribution of book-mediated learning, and accepted that using a book can be fun, practical, and can help develop students' cognitive abilities. Findings seem to indicate that all of the participants agreed that they did not obtain new information from the book regarding ADHD. However, this teachers' claim that the experience of teaching using the book as a mediating tool led them to view books as an additional teaching tool. In other words, they found it useful as an additional source for varying the teaching process. According to the teachers, the book provided an alternative 
way to convey a message, an experiential method that afforded a different kind of interaction between students and the contents studied. It appears that, in general, teachers wish their students to experience a process that has a broad range of personal, social, and developmental repercussions. Furthermore, the teachers' goal is that their students have a reading experience that is not intended solely for teaching purposes, and that this process be followed by students' engaging in an attempt to construct meaning. According to the findings, the book changed both the students' self-image and the teachers' approach to ADHD. These effects resulted from an emotional process that enabled a discussion of a type that could not have occurred otherwise, as well as from the experience of identifying with the other-both processes which were enabled through the use of the book.

According to findings, teachers did not make a regular effort to use this tool. Especially noticeable was their lack of motivation to seek out books independently and to use them as they saw fit and according to the advantages that they identified, as they might have been expected to do. An important point that the teachers raised and which merits further consideration relates to the stage of professional teacher training, which according to the teachers did not equip them to cope on a personal level with students' emotional responses and reactions. Teachers claimed they lacked practical tools for dealing with this aspect. Based on the teachers' responses, it appears that the book did in fact serve as a therapeutic tool. As a therapeutic tool, the book enabled teachers to apply a dimension of personal expression, which could be used for conveying emotion. The book could provide a helpful way for teachers to get a glimpse into the students' inner world. The book initiates a search for the self, in an attempt to discover its true nature. However, if the book did function as a significantly useful tool, why then did the teachers not relate to it as a therapeutic instrument? The teachers did not appear to perceive the book as a therapeutic tool; rather, they seemed to view its importance as secondary, compared to other therapeutic methods they mentioned, but which are beyond the scope of the current study.

In addition to the explanation regarding lack of fiscal and time-related resources, teachers also noted their lack of experience using tools related to the bibliotherapeutic process. They referred to the fact that they had never learned about it in their training. It seems that their lack of knowledge about this tool, coupled with their fear of using it incorrectly, created the noticeable disparity between their understanding and appreciation of the importance of using the book as a tool, on the one hand, and their practice of refraining from using books for this purpose, on the other hand. Morowski (1997) claims, those teachers should have an abundance of knowledge in bibliotherapy. Properly used, this tool can contribute to teachers' personal and professional development, as long as teachers' range of responsibility encompasses only the realm of developmental bibliotherapy. Teachers should know when to seek help from a professional bibliotherapist. To ensure that the process is optimally adapted to the particular situation, it is best to follow a structured model. Hence, it is important to expose teachers-in-training to the importance and contribution of bibliotherapy, as a tool that first and foremost is helpful to the teacher, and as teachers become more familiar and comfortable with it, they will be better able to use it in a precise and efficient manner in the classroom.

Based on the information provided by the teachers, it is worth rethinking the curriculum and including in it tools and processes of bibliotherapy that can be used in the classroom, or, alternatively, inviting professionals from the field of bibliotherapy into the classroom. Morowski's study (1997) provides support for the importance of the bibliotherapeutic process. She claims that educators are responsible for students developing into mature and mentally healthy individuals, who have an appropriate set of social skills and a clearly defined, value-based worldview. Teachers who are aware of the inner world and needs of their students may help strengthen students' self-image and confidence, and provide a protective learning environment founded on a set of value-based rules and regulations. According to Morawski, teachers must be prepared and have the skills to create a learning environment that addresses students' cognitive, emotional, and moral needs. Indeed, the teacher should be well-equipped in terms of knowledge in bibliotherapy.

The findings garnered in the current study demonstrate that by means of an experiential process that includes using a book as a mediating tool, it is possible to affect teachers' educational values. Teachers reported experiencing an emotional process following their exposure to and experimentation with the bibliotherapeutic process, and they also expressed their desire and willingness to continue the process beyond the framework of the study. Teachers raised the possibility of including in the framework of teachers' professional training a module on the use of books as a mediating tool, which should provide teachers with a clearly-defined framework, in terms of time and space, for using this process. The need arises from teachers' daily reality, in which they are expected to meet goals defined for them by the Ministry of Education and by their particular school.

\section{References}

Avisar, G., \& Laser, Y. (2000). Evaluating changes in special education as an educational change. From Theory to 
Practice, 15, 97-124 (in Hebrew).

Balas, N., \& Laor, A. (2002). Special education In Israel and the inclusion policy. Jerusalem: Publisher? (in Hebrew).

Baratz, L., \& Kass, E. (2007). The book shelf: Enemy or friend? Tel Aviv: Mofet Institute (in Hebrew).

Catalano, A. (2008). Making a place for bibliotherapy on the shelves of a curriculum materials center: The case for helping pre-service teachers use developmental bibliotherapy in the classroom. Education Libraries, 31(1), $17-22$.

Cochran-Smith, M. (1986). Reading to children: A model for understanding texts. In B. Schieffelin, \& P. Gilmore (Eds.), The Acquisition of Literacy: Ethnographic Perspectives (pp. 35-55). Norwood, N.J: Ablex Publishing Corporation.

Dar'in, A. (2001). The hyperactive child. Tel Aviv: Ach (in Hebrew).

De Malach, N., \& Poise, Y. (2006). I couldn't define a good story: Students of education critique a story. Dapim, 42, 154-181 (in Hebrew).

Feuerstein, R. (1979). The dynamic assessment of retarded performers. Baltimore University Park Press.

Feuerstein, R. (1980). Instrumental enrichment: Redevelopment of cognitive functions of retarded performers. New York: University Park Press.

Glaser, B. G., \& Strauss, A. L. (1967). The constant comparative method of qualitative analysis. In The Discovery of Grounded Theory (pp. 101-115). New York: Aldine.

Karen W. G., \& Stephanie K. (2011). Using Children's and Young Adult Literature, Teaching Acceptance and Understanding of Individual Difference. The Delta Kappa Gamma Bulletin, 77(2), 11-16.

Klein, S. P. (1996). Early intervention: Cross-cultural experiences with a mediational approach. N.Y. and London: Garland Pub. Inc.

Lindsay, N. (2006). Bringing home the world. School Library Journal, 52(2), 36-37.

Margalit, M. (1997). Constantly in motion. Tel Aviv: Sifriyat HaPoalim (in Hebrew).

Marlowe, M., \& Maycock, G. (2000). Phenomenology of bibliotherapy in modifying teacher punitiveness. Journal of Genetic Psychology, 161(3), 325-336. http://dx.doi.org/10.1080/00221320009596715

Morawski, M. C. (1997). A role for bibliotherapy in teacher education. Reading Horizons, 37, 243-259.

Prater, M. A., Johnstun, M. L., Dyches, T. T., \& Johnstun, M. R. (2006). Using children's books as bibliotherapy for at-risk students: A guide for teachers. Preventing School Failure: Alternative Education for Children and Youth, 50(4), 5-10. http://dx.doi.org/10.3200/PSFL.50.4.5-10

Rosenthal, A. (2006). Values inherent in children's literature in early childhood education in the public education system. Sifrut Yeladim Vanoar, A(125), 16-42 (in Hebrew).

Sacerdoti, Y. (2013). Not exactly what you wanted: The encounter between the "typical" child and the child with special needs in Israeli children's literature. Miscellanea, 6, 133-149 (in Hebrew).

Shach, A., \& Green-Shukrun, R. (2009). Attracting teacher trainees to children's literature through experiential activities. Bamichlala-Issues in Training and Guidance for Early Childhood Education, 22, 181-208 (in Hebrew).

Shavit, Z. (1996). Childhood Stories: Introduction to the Poetics of Children's Literature. Tel-Aviv: The Open University.

Tal, K. (2010). Reading comprehension: The way children understand picture books and what can we do to make them love (to read) books? Reverberations from Kindergarten, B, 6-12 (in Hebrew).

Talmor, R., Asia, S., \& Kayam, A. (2010). Teachers' attitudes towards children with special needs compared to their attitudes towards mainstream children: The qualitative study. Issues in Special Education and Inclusion, 25(1), 5-21 (in Hebrew). 


\section{Copyrights}

Copyright for this article is retained by the author(s), with first publication rights granted to the journal.

This is an open-access article distributed under the terms and conditions of the Creative Commons Attribution license (http://creativecommons.org/licenses/by/3.0/). 